\title{
PENETAPAN KADAR ALKOHOL PADA MINAS (MINUMAN KHAS SINJAI) YANG DIPERJUALBELIKAN DI KOTA SINJAI
}

\author{
Rahmawati $^{1)}$, Musfirah ${ }^{1)}$, Nurul Ni’ma Azis, Andi Asri Yustika Rifada ${ }^{1)}$ \\ ${ }^{1)}$ Prodi D3 Teknologi Laboratorium Medis Politeknik Kesehatan Muhammadiyah Makassar \\ Alamat korenspondensi: rahmawatiamma60@gmail.com
}

\begin{abstract}
Abstrak
Minuman beralkohol merupakan sejenis minuman yang sering dikonsumsi oleh masyarakat. MINAS atau minuman khas Sinjai merupakan minuman yang terbuat dari tapai singkong dan beberapa tambahan lainnya. Tapai singkong merupakan makanan tradisional yang sangat populer di Indonesia dan diperoleh dari proses fermentasi yang produk akhirnya akan menghasilkan alkohol. Menurut Peraturan Kepala Badan Pengawas Obat dan Makanan Republik Indonesia No. 14 Tahun 2016 tentang standar keamanan dan mutu makanan beralkohol dan minuman beralkohol adalah tidak lebih dari 0,01\%. Tujuan dari penelitian ini untuk menentukan kadar alkohol pada MINAS yang diperjualbelikan di Kota Sinjai, dengan enis penelitian yaitu observasi laboratorik. Berdasarkan hasil penelitian menggunakan metode Alkalimetri didapatkan nilai rata-rata kadar alkohol dalam MINAS pada 10 sampel berturut-turut sebesar 0.1338\%, $0.1758 \%, 0.1835 \%, 0.1804 \%, 0.1628 \%, 0.2069 \%, 0.1447 \%, 0.1369 \%, 0.2940 \%$, dan $0.1804 \%$. Hal ini dapat disimpulkan bahwa kadar alkohol pada MINAS melebihi ambang batas yang telah ditetapkan oleh Badan Pengawas Obat dan Makanan Republik Indonesia No.14 Tahun 2016 yaitu $0.01 \%$.
\end{abstract}

Kata kunci: MINAS, Kadar Alkohol, Metode Alkalimetri

\section{PENDAHULUAN}

Minuman beralkohol merupakan sejenis minuman yang sering dikonsumsi oleh manusia. Minuman beralkohol adalah minuman yang mengandung etanol yang diproses dari bahan hasil pertanian yang mengandung karbohidrat dengan cara fermentasi dan destilasi atau fermentasi tanpa destilasi, baik dengan cara memberi perlakuan terlebih dahulu atau tidak, menambahkan bahan lain atau tidak, maupun yang diproses dengan cara mencampur konsentrat dengan alkohol atau dengan cara pengenceran minuman yang mengandung etanol (Nugroho, 2013). Salah satu minuman beralkohol khas Kota Sinjai yang terkenal di masyarakat setempat maupun luas adalah MINAS.

MINAS yang artinya minuman khas Sinjai dulunya dikenal dengan nama Irex. Akan tetapi, seiring berjalannya waktu minuman ini diganti dengan nama MINAS karena hanya diproduksi di Kota Sinjai dan dijadikan sebagai minuman khas Sinjai. MINAS merupakan jenis minuman yang tidak dapat bertahan lama, karena tidak bisa diawetkan. Minuman ini enak dikonsumsi dalam keadaan dingin serta memiliki khasiat dan manfaat untuk menambah stamina tubuh akibat kelelahan setelah melakukan aktivitas atau pekerjaan sehari-hari. MINAS terbuat dari tapai singkong, kelapa muda, telur, air kelapa, air gula, madu, dan susu serta dapat ditambahkan dengan buahbuahann lainnya seperti durian.

Tapai merupakan makanan tradisional yang sangat populer di Indonesia. Tapai biasanya dibuat dari beras ketan dan singkong yang kaya akan kandungan karbohidrat (Wulandari dkk, 2011). Menurut Hasanah dkk (2012), tapai adalah produk yang dihasilkan dari proses fermentasi, di mana zat pati yang terdapat dalam bahan makanan diubah menjadi bentuk yang lebih sederhana yaitu gula, dengan bantuan suatu mikroorganisme yang disebut ragi atau khamir. Ragi tapai adalah bahan yang 
dapat digunakan dalam pembuatan tapai, baik dari singkong dan beras ketan.

Fermentasi merupakan proses yang relatif murah yang pada hakekatnya telah lama dilakukan secara tradisional dengan produk-produknya yang sudah biasa dikonsumsi oleh masayarakat. Proses fermentasi ini akan menghasilkan alkohol dan $\mathrm{CO}_{2}$. Dari hasil penelitian Hasanah dkk (2012) menunjukkan bahwa ada pengaruh lama fermentasi terhadap kadar alkohol tapai singkong. Kadar etanol pada sampel tapai singkong selama 24 jam, 48 jam, 72 jam, 96 jam, dan 120 jam diperoleh hasil berturut-turut sebesar $0,844 \%, 2,182 \%, 4,904 \%, 6,334 \%$ dan $11,811 \%$. Lama fermentasi 120 jam berpengaruh sangat nyata pada kadar alkohol tapai singkong diantara lama fermentasi lainnya.

Selain itu, berdasarkan dari hasil penelitian Tongkasi (2018) tentang analisis kadar alkohol pada tapai singkong (Manihot utilissima) yang diperjualbelikan di Kota Makassar, didapatkan hasil nilai kadar alkohol dalam tapai singkong pada sampel 1 sebesar $0.338 \%$, sampel 2 sebesar $0.512 \%$, sampel 3 sebesar $0.547 \%$, sampel 4 sebesar $0.362 \%$, dan sampel 5 sebesar $0.374 \%$.

Menurut Badan Pengawas Obat dan Makanan Republik Indonesia No. 14 Tahun 2016 tentang standar keamanan dan mutu makanan beralkohol dalam minuman beralkohol adalah tidak lebih dari $0,01 \%$. Apabila alkohol yang masuk kedalam tubuh melebih ambang batas tersebut dapat menyebabkan adanya gangguan kesehatan seperti mual, muntah, penurunan kesadaran, kejang, menyebabkan iritasi, serta gangguan emosional. Konsumsi alkohol yang berjangka panjang dapat menyebabkan sirosis hati, koma bahkan kematian.

Berdasarkan latar belakang di atas, maka penulis melakukan pengkajian secara ilmiah dengan judul "Penetapan Kadar Alkohol Pada Minuman Khas
Sinjai (MINAS) yang Diperjualbelikan Di Tempat Pelelangan Ikan Kota Sinjai".

\section{METODE PENELITIAN}

\section{Alat dan Bahan}

Alat yang digunakan untuk erlenmeyer, neraca analitik, labu ukur 500 $\mathrm{mL}$ dan $50 \mathrm{~mL}$, gelas kimia, gelas ukur, buret 1 set, cawan porselin, batang pengaduk, dan pipet tetes.

Bahan yang digunakan dalam penelitian ini adalah sampel MINAS, aquadest, indikator PP (phenolphtalein) $1 \%$, larutan $\mathrm{NaOH} 0,1 \mathrm{~N}$ dan asam oksalat.

\section{Prosedur Penelitian}

\section{Pembuatan Larutan $\mathrm{NaOH} 0,1 \mathrm{~N}$}

Sebanyak 2, $25 \mathrm{~g} \mathrm{NaOH}$ ditimbang lalu dilarutkan dengan aquadest. Selanjutnya dimasukkan ke dalam labu ukur $500 \mathrm{~mL}$, tambahkan aquadest sampai tanda batas. Dihomogenkan lalu disimpan dalam botol reagen tertutup. (Rahmawati \& Rostinah, 2016).

Pembuatan Larutan Indikator PP (phenolphtalein) 1\%

Indikator PP ditimbang sebanyak $0,5 \mathrm{~g}$ lalu dilarutkan dengan $25 \mathrm{~mL}$ etanol. Selanjutnya dimasukkan ke dalam labu ukur $50 \mathrm{~mL}$, ditambahkan aquadest sampai tanda batas. dihomogenkan lalu di simpan dalam botol reagen tertutup.

\section{Standarisasi NaOH 0,1 N}

Sebelum dilakukan pengujian, terlebih dahulu dilakukan standarisasi $\mathrm{NaOH} 0,1 \mathrm{~N}$. Mula-mula ditimbang 0,11 $\mathrm{g}$ asam oksalat lalu dilarutkan dalam 100 $\mathrm{mL}$ aquadest. Selanjutnya diambil $25 \mathrm{~mL}$ larutan dimasukkan ke dalam erlenmeyer. Ditambahkan 3 tetes indikator PP (Phenolphthalein) 1\%. Kemudian dititrasi dengan $\mathrm{NaOH} \quad 0,1 \quad \mathrm{~N}$ sampai larutan berubah warna menjadi merah muda. Setelah berubah warna, titrasi dihentikan kemudian lihat volume larutan $\mathrm{NaOH} \mathrm{0,1}$ $\mathrm{N}$ yang digunakan. Dicatat hasil yang didapatkan (Tim Analitik UPI, 2001).

Analisis Kuantitatif Alkohol dengan Metode Titrimetri

Sampel MINAS yang telah diperoleh sebanyak 10 sampel. Tiap 
sampel masing-masing ditimbang sebanyak 10 gram, dimasukkan dalam erlenmeyer dan ditambahkan aquadest 50 $\mathrm{mL}$ dan indikator PP (Phenolphthalein) $1 \% 3$ tetes. Setelah itu dihomogenkan kemudian dititrasi dengan larutan $\mathrm{NaOH}$ 0,1 N sampai larutan berubah warna menjadi merah muda. Setelah berubah warna, dihentikan titrasi, kemudian dilihat volume larutan $\mathrm{NaOH} \quad 0,1 \quad \mathrm{~N}$ yang digunakan. Selanjutnya jumlah volume yang didapatkan digunakan untuk menghitung kasar kadar alkohol yang terkandung dalam MINAS. Selanjutnya data yang diperoleh dimasukkan dalam pengamatan, kemudian dihitung besarnya kadar alkohol dalam minuman MINAS dengan rumus (Tim Analitik UPI, 2001).

\section{HASIL PENELITIAN}

Penelitian dilaksanakan pada tanggal 4-30 April 2019 dan bertempat di laboratorium kimia dan toksikologi klinik Politeknik Kesehatan Muhammadiyah Makassar untukpenetapan kadar alkohol pada MINAS yang diperjualbelikan di Kota Sinjai, diperoleh hasil sebagai berikut:

Tabel 1. Hasil perhitungan standarisasi $\mathrm{Na}_{2} \mathrm{~S}_{2} \mathrm{O}_{3} 0,1 \mathrm{~N}$ dengan $\mathrm{KIO}_{3}$

\begin{tabular}{ccc}
\hline Erlenmeyer & $\begin{array}{c}\text { Volume } \\
\text { Titrasi }\end{array}$ & Normalitas \\
\hline 1 & $4.3 \mathrm{~mL}$ & $0.1015 \mathrm{~N}$ \\
2 & $4.4 \mathrm{~mL}$ & $0.0992 \mathrm{~N}$ \\
3 & $4.2 \mathrm{~mL}$ & $0.1038 \mathrm{~N}$ \\
\hline \multicolumn{2}{c}{ Rata-Rata } & $0,1015 \mathrm{~N}$ \\
\hline
\end{tabular}

Tabel 2.Hasil Pemeriksaan Kadar Alkohol Pada MINAS yang Diperjualbelikan Di Kota Sinjai

\begin{tabular}{cccc}
\hline Sampel & $\begin{array}{c}\text { Volume } \\
\text { Titrasi } \\
(\mathbf{m L})\end{array}$ & $\begin{array}{c}\text { Kadar } \\
\text { Alkohol } \\
(\boldsymbol{\%})\end{array}$ & $\begin{array}{c}\text { Rata-Rata } \\
(\boldsymbol{\%})\end{array}$ \\
\hline \multirow{2}{*}{1} & $\mathrm{~V}_{1}=2.9$ & 0.1354 & \\
& $\mathrm{~V}_{2}=2.9$ & 01354 & 0.1338 \\
& $\mathrm{~V}_{3}=2.8$ & 0.1307 & \\
& $\mathrm{~V}_{1}=3.3$ & 0.1540 & \\
2 & $\mathrm{~V}_{2}=3.9$ & 0.1820 & 0.1758 \\
& $\mathrm{~V}_{3}=4.1$ & 0.1914 & \\
3 & $\mathrm{~V}_{1}=3.6$ & 0.1680 & \\
3 & $\mathrm{~V}_{2}=4.3$ & 0.2007 & 0.1835 \\
\hline
\end{tabular}

\begin{tabular}{cccc}
\hline & $\mathrm{V}_{3}=3.9$ & 0.1820 & \\
& $\mathrm{~V}_{1}=3.3$ & 0.1540 & \\
& $\mathrm{~V}_{2}=3.9$ & 0.1820 & 0.1804 \\
& $\mathrm{~V}_{3}=4.4$ & 0.2054 & \\
5 & $\mathrm{~V}_{1}=3.9$ & $0.1820 \%$ & \\
& $\mathrm{~V}_{2}=3.1$ & 0.1447 & 0.1628 \\
& $\mathrm{~V}_{3}=2.7$ & 0.1260 & \\
& $\mathrm{~V}_{1}=4.5$ & 0.2101 & \\
6 & $\mathrm{~V}_{2}=4.5$ & 0.2101 & 0.2069 \\
& $\mathrm{~V}_{3}=4.3$ & 0.2007 & \\
& $\mathrm{~V}_{1}=4.3$ & 0.2007 & \\
7 & $\mathrm{~V}_{2}=3.1$ & 0.1447 & 0.1447 \\
& $\mathrm{~V}_{3}=3.6$ & 0.1680 & \\
& $\mathrm{~V}_{1}=2.6$ & 0.1213 & \\
8 & $\mathrm{~V}_{2}=2.9$ & 0.1354 & 0.1369 \\
& $\mathrm{~V}_{3}=3.3$ & 0.1540 & \\
& $\mathrm{~V}_{1}=5.5$ & 0.2567 & \\
9 & $\mathrm{~V}_{2}=6.2$ & 0.2894 & \\
& $\mathrm{~V}_{3}=7.2$ & 0.3361 & \\
& $\mathrm{~V}_{1}=4.9$ & 0.2287 & \\
\multirow{2}{*}{10} & $\mathrm{~V}_{2}=3.6$ & 0.1680 & 0.1804 \\
& $\mathrm{~V}_{3}=3.1$ & 0.1804 & \\
\hline
\end{tabular}

\section{PEMBAHASAN}

Dari hasil perhitungan kadar alkohol pada MINAS didapatkan hasil pada 10 sampel dengan nilai rata-rata kadar alkohol berturut-turut yaitu $0.1338 \%, 0.1758 \%, 0.1835 \%, 0.1804 \%$, $0.1628 \%, 0.2069 \%, 0.1447 \%, 0.1369 \%$, $0.2940 \%$, dan $0.1804 \%$. Dari 10 sampel tersebut didapatkan kadar alkohol yang berbeda-beda dimana kadar alkohol yang paling tinggi terdapat pada sampel 9 yaitu $0.2940 \%$. Menurut Peraturan Kepala Badan Pengawas Obat dan Makanan Republik Indonesia NO. 14 Tahun 2016 tentang standar keamanan dan mutu makanan beralkohol dan minuman beralkohol adalah tidak lebih dari $0.01 \%$. Maka didapatkan bahwa sampel MINAS melebihi ambang batas yaitu $0.01 \%$.

Kadar alkohol yang meningkat dalam MINAS dapat dipengaruhi oleh ragi yang terdapat di dalam bahan dasarnya yaitu tapai singkong. Pembuatan tapai singkong dilakukan dengan cara mengupas terlebih dahulu bagian kulit singkong, kemudian singkong dicuci dengan bersih. Selanjutnya singkong dikukus hingga matang. Singkong yang sudah dikukus kemudian dibiarkan hingga 
dingin. Selama menunggu singkong dingin, menyiapakan dan membersihkan pembungkus dari daun pisang atau plastik agar betul-betul steril.

Singkong yang sudah dingin kemudian dicampur dengan ragi lalu dibungkus dengan daun pisang atau plastik dan diusahan dalam membungkusnya rapat agar udara tidak masuk kedalam bahan dan mengganggu proses fermentasi. Memasukkan singkong yang telah dibungkus daun pisang ke dalam wadah plastik atau keranjang yang kedap udara dan menutupnya rapat-rapat agar proses fermentasi berjalan dengan maksimal serta mencegah terjadinya kegagalan pada proses fermentasi. Singkong dibiarkan selama 2 hari untuk proses fermentasi. dan pada hari ketiga, sigkong dibuka dari bungkus daun pisang.

Tapai singkong yang mengalami proses fermentasi, di mana zat pati yang terdapat dalam singkong diubah menjadi bentuk yang lebih sederhana yaitu gula dengan bantuan suatu mikroorganisme yang disebut ragi atau khamir. Pada sampel 1 dan 2 ragi yang dipakai pada 1 $\mathrm{kg}$ singkong yaitu sebanyak 2 butir ragi, pada sampel 3 dan 4 serta sampel 5 dan 6 sebanyak 3 butir ragi, pada sampel 7 dan 8 sebanyak 1 butir ragi sedangkan sampel 9 dan 10 sebanyak 5 butir ragi. Semakin banyak ragi yang digunakan maka semakin tinggi pula kadar alkohol yang akan dihasilkan. Hal ini juga sejalan dengan penelitian yang telah dilakukan sebelumnya oleh Berlian (2016) yang menyatakan bahwa semakin tinggi konsentrasi ragi yang ditambahkan maka akan menghasilkan kadar alkohol yang semakin tinggi, karena mempunyai khamir yang semakin banyak pula. Khamir tersebut yang bekerja pada proses fermentasi dengan merombak glukosa menjadi alkohol.

Menurut Fahmi \& Nurrahman (2011), reaksi dalam fermentasi berbedabeda tergantung pada jenis gula yang digunakan dan produk yang dihasilkan. Selain itu jumlah karbohidrat dalam sigkong dapat mempengaruhi rasa manis, karena karbohidrat akan dipecah menjadi glukosa selama proses fermentasi. Secara singkat glukosa $\left(\mathrm{C}_{6} \mathrm{H}_{12} \mathrm{O}_{6}\right)$ yang merupakan gula paling sederhana, melalui fermentasi akan menghasilkan etanol $\left(2 \mathrm{C}_{2} \mathrm{H}_{5} \mathrm{OH}\right)$. Reaksi fermentasi ini dilakukan oleh ragi dan digunakan pada produksi makanan.

Persamaan reaksi kimia:

$\mathrm{C}_{6} \mathrm{H}_{12} \mathrm{O}_{6}$
ATP

Selain dari ragi yang digunakan pada bahan dasar MINAS, bahan tambahan dari MINAS juga dapat menyebabkan tingginya kadar alkohol pada MINAS. MINAS yang dibuat dengan cara menghaluskan tapai singkong dengan blender kemudian ditambahkan dengan susu, telur, madu, air gula, air kelapa dan kelapa muda yang telah dihaluskan terlebih dahulu. Dari bahanbahan tersebut air kelapa juga dapat mempengaruhi tingginya kadar alkohol pada MINAS. Menurut Sutarminingsih (2004) air kelapa akan berubah sifat akibat adanya fermentasi dan kontaminasi bakteri lain. Air kelapa berubah menjadi asam akibat aktifitas bakteri Acetobacter pada air kelapa yang mengandung alkohol. Alkohol tersebut mengalami penggabungan dengan oksigen dan berubah menjadi acctaldehid. Pada akhirnya acctaldehid akan mengalami oksidasi menjadi asam asetat.

Dampak toksisitas jika mengkonsumsi alkohol dalam hal ini mengacu pada kesehatan. Apabila masyarakat mengkonsumsi makan atau minuman yang mengandung alkohol dalam jangka pendek dapat menyebabkan iritasi, gangguan emosional, gangguan koordinasi motorik, takikardi, berkeringat, mual, muntah, penurunan kesadaran, kejang, hingga koma. Sedangkan apabila mengkonsumsi alkohol dalam jangka 
waktu panjang dapat menyebabkan terjadinya sirosis hati (Julia 2016).

\section{KESIMPULAN DAN SARAN}

Berdasarkan hasil penelitian didapatkan nilai kadar alkohol pada MINAS yang terdapat pada 10 sampel berturut-turut yaitu $0.1338 \%, 0.1758 \%$, $0.1835 \%, 0.1804 \%, 0.1628 \%, 0.2069 \%$, $0.1447 \%, \quad 0.1369 \%, \quad 0.2940 \%$, dan $0.1804 \%$. Maka dapat disimpulkan bahwa kadar alkohol pada MINAS melebihi ambang batas yang diatur oleh Badan Pengawas Obat dan Makanan Republik Indonesia No.14 Tahun 2016 yaitu $0.01 \%$.

Saran bagi para peneliti selanjutnya, perlu diteliti kadar alkoholnya dengan penggunaan ragi tapai singkong yang lebih bervariasi dan menggunakan motede lain seperti Spektrofotometri.

\section{DAFTAR PUSTAKA}

Apriwinda. 2013. Studi Fermentasi Nira Batang Sorgum Manis (Sorghum bicolor (L) Moench) Untuk Produksi Etanol. Skripsi. Makassar: Jurusan Teknologi Pertanian Fakultas Pertanian Universitas Hasanuddin.

Berlian. Z, Aini. F, Ulandari. R. 2016. Uji Kadar Alkohol Pada Tapai Ketan Putih Dan Singkong Melalui Fermentasi Dengan Dosis Ragi Yang Berbeda. Prodi Pendidikan Biologi, Fakultas Tarbiyah dan Keguruan, UIN Raden Fatah Palembang. Jurnal Biota, 2 (1): 106 -111 .

Fahmi. N., Nurrahman. 2011. Kadar Glukosa, Alkohol Dan Citarasa TAPAI Onggok Berdasarkan Lama Fermentasi. Program Studi Teknologi Pangan Universitas Muhammadiyah Semarang. Jurnal Pangan dan Gizi, 2 (3): 25 - 42.
Hasanah. H., Jannah. A., Fasy. A. G. 2012. Pengaruh Lama Fermentasi Terhadap Kadar Alkohol Tape Singkong (Manihot utilissima Pohl). Jurusan Kimia, Fakultas Sains dan Teknologi, UIN Maulana Malik Ibrahim Malang. Jurnal Alchemy, 2 (1): 68-79.

Julia, S. R. 2016. Efek Minuman Keras Oplosan terhadap Perubahan Hispatologi Lambang Tikus Wistar Jantan. Skripsi. Fakultas Kedokteran Jember.

Nugroho, W. S. 2013. Pengaruh Pendidikan Kesehatan terhadap Pengetahuan dan Sikap Remaja Putra tentang Bahaya Minuman Keras Di Desa Blulukan Colomadu Karangayar. Naskah Publikasi. Fakultas Ilmu Kesehatan, Universitas Muhammadiyah. Surakarta.

Peraturan Kepala Badan Pengawas Obat dan Makanan Republik Indonesia Nomor 14 Tahun 2016 tentang Standar Keamanan dan Mutu Minuman Beralkohol.

Rahmawati \& Rustinah, W. O., 2016 Penuntun Praktikum Kimia Analitik II. Makassar: Akademi Analis Kesehatan Muhammadiyah.

Suaniti. N. M. 2015. Kadar Etanol Dalam Tape Sebagai Hasil Fermentasi Beras Ketan (Oryza sativa glutinosa)Dengan Saccaromyces cerevisiae. Jurusan Kimia F.MIPA Universitas Udayana, Bukit Jimbaran. Jurnal Virgin, 1 (1): 1619.

Sutarminingsih, L. 2004. Peluang Usaha Nata De Coco. Kanisius. Yogyakarta.

Tim Kimia Analitik UPI. 2001. Petunjuk Praktikum Kimia Analitik I. Bandung: Diterbitkan oleh JICAFPMIPA UPI 
Tongkasi, M. I. 2018. Analisis Kadar Alkohol Pada Tapai Singkong (Manihot utilissima) yang Diperjualbelikan Di Kota Makassar. Karya Tulis Ilmiah. Makassar: Akademi Analis Kesehatan Muhammadiyah.

Utami. A. T., Noviyanti. L. 2010. Pembuatan Tape Dari Ubi Kayu (Manihot utilissima) yang Tahan Lama. Skripsi. Surakarta: Fakultas Teknik, Universitas Sebelas Maret.
Wulandari, B. E., Harlita, Muzzayinah. 2011. Implementasi Hasil Penelitian identifikasi Fungi pada Talas (Colocasia esculenta) sebagai Sumber Belajar Berupa Modul pada Pokok Bahasan Fungi terhadap Keterampilan Menginterpretasi Data Siswa Kelas X SMA Al Islam 1 Surakarta Tahun Ajaran 2011/2012. Pendidikan Biologi FKIP UNS. Jurnal Pendidikan Bioloogi. 3 (2): $65-$ 76. 